\title{
Pentecostalismo e questão racial no Brasil: desafios e possibilidades do ser negro na igreja evangélica'
}

\author{
Pentecostalism and racial issue in Brazil: challenges and \\ possibilities for being Black within the church
}

\section{Morgane Laure Reina ${ }^{a}$}

Resumo Em um contexto de crescente intolerância religiosa no Brasil e dada a importância do pentecostalismo para a população negra, a relação entre fiéis negros e sua igreja torna-se um tema importante para a academia, embora seja pouco estudado e ainda mal delimitado. O objetivo deste artigo é estudar as possibilidades e os desafios para os negros de reivindicar sua etnicidade e historicidade dentro da comunidade eclesial: qual é o lugar dos fiéis negros - como indivíduos não branqueados - na igreja? Quais são as possibilidades de reconhecimento da sua identidade negra? Qual identidade deve ser reivindicada? Apesar de certa ausência desta discussão teórica em pesquisas sociológicas, este trabalho se baseia em uma revisão crítica da limitada literatura, aprofundada por uma observação participante e entrevistas. Apresenta um desafio heurístico e metodológico que busca uma melhor compreensão da questão da intolerância racial, cultural e religiosa na igreja evangélica. Nesta perspectiva, esta reflexão propõe uma abordagem interdisciplinar entre a sociologia da religião e a sociologia das relações e das desigualdades raciais, no fim de explorar que não há necessariamente um antagonismo entre a identidade negra e a identidade cristã.

Palavras-chave Protestantismo evangélico; Fiéis negros; Identidade negra; Religiões de matriz africana; Intolerância.

Abstract In a context of growing religious intolerance in Brazil and given the relevance of Pentecostalism to the black population, the relationship between black believers and their church becomes an important, though understudied, research question. The objective of this article is to study the possibilities and challenges for black churchgoers to express their ethnicity and their historicity within the ecclesiastic community: what is the place of black believers as non-whitened people in church? What are the

1 Uma versão resumida deste mesmo trabalho foi apresentada na Primeira Jornada de Estudos Negros da UnB, dia 04 de novembro de 2016. Disponível em: (p. 209) https://calundublog.files. wordpress.com/2017/02/anais-da-i-jornada-de-estudos-negros-da-unb.pdf Acessado em: 14 de novembro de 2017.

a Formada em Ciências Humanas pela Sciences Po Paris, mestra em Sociologia Política Comparada pela mesma instituição, e doutoranda pelo Departamento de Sociologia da Universidade de Brasília (UnB). 
possibilities of recognition of their black identity? Which identity should be claimed? What about their African heritage? Despite the lack of this theoretical discussion in sociological studies, this study is based on a critical review of the limited literature and deepened by participant observation and interviews. It stands as a heuristic and methodological challenge that seeks a better understanding of the issue of racial, cultural and religious intolerance in the Evangelical church. That considered, this reflection proposes an interdisciplinary approach between sociology of religion and sociology of race relations and racial inequalities, in order to further explore that there is not necessarily an antagonism between the black identity and Christian identity. Keywords Evangelical Protestantism; Black churchgoers; Black identity; AfricanBrazilian religions; Intolerance.

\section{INTRODUÇÃO}

O que significa a observação de Roger Bastide (1960) sobre o fato de os negros não entrarem mais pela porta lateral da igreja? Em termos absolutos, os números mostram que "há mais evangélicos negros do que praticantes das religiões afrobrasileiras e as religiões evangélicas são as que mais crescem no Brasil das últimas décadas" (SiLva, 2011, p. 298). Esse dado fala por si só da relevância de se interessar à questão negra dentro da igreja evangélica ${ }^{2}$, embora seja pouco estudada e ainda mal delimitada. No entanto, desde os anos 1960, o movimento negro e as ciências sociais refletem sobre diversos aspectos que compõem esta problemática. Nessa continuidade, o presente artigo propõe repensar e aprofundar a reflexão sobre esta questão.

O objeto de estudo deste trabalho constitui, simultaneamente, um desafio em termos heurísticos e metodológicos. Em primeiro lugar, há uma falta de consenso sobre a identidade negra, noção que queremos desenvolver aqui em relação às igrejas. A sociologia vem demonstrando que não existe uma identidade social fixa, atemporal. Toda identidade é o resultado de um processo de construção social e histórica. No entanto, este trabalho se inscreve na perspectiva de Abdias do Nascimento (1980) que vê na formação da identidade negra o desenvolvimento e na adaptação no Brasil de instituições, valores e atitudes trazidos da África. Ademais, como precisam Fernandes e Souza (2016), em referência a Guimarães (2003), ela é ligada "à cultura e ao restabelecimento da memória histórica da diáspora africana" (p.105). Também levamos em conta que a adoção do termo identidade para definir

2 Apesar do termo evangélico designar, de maneira abrangente, todos os protestantes, neste trabalho o termo será usado para designar, na maior parte dos casos, os protestantes pentecostais. 
social ou racialmente um grupo visa geralmente a objetivos como a proteção e a defesa de uma minoria ou de interesses, a reversão de lógicas de opressão, entre outros. As reivindicações históricas de movimentos sociais como o Movimento Negro Unificado (MNU) e as afirmações legais como a lei 10.639/o3 levaram à inclusão de conteúdo pedagógico sobre a História da África e das Culturas Afro-brasileiras no ensino fundamental, proporcionando o reconhecimento da herança cultural africana ${ }^{3}$ na identidade negra no Brasil, apesar da falta de consenso por parte de setores mais conservadores da arena política e da sociedade.

Em segundo lugar, na falta de definição do que pode ser a identidade negra dentro da igreja, vários autores escolheram tratar de temas relacionados, passando à margem da elaboração do termo. $\mathrm{O}$ que esperar de uma literatura que estuda os negros evangélicos ou crentes negros? A maior entrada para o tema parece ser o conflito entre as religiões evangélica e de matriz africana, sob a perspectiva de uma intolerância evangélica (SILvA, 2011; ORO, 1997). Porém, parte da literatura sociológica, que pouco explora a questão negra nas igrejas evangélicas, muitas vezes deixa de lado instrumentos de sociologia das relações raciais, mesmo para estudar a questão da perseguição das religiões de matriz africana. No entanto, outros estudos se interessam, de forma detalhada, pelas percepções dos fiéis (BURDICK, 2002) e pelas ressignificações da herança africana; porém, parece árdua a tarefa de superar o antagonismo entre pentecostalismo e questão negra, isto é: a impossibilidade para o crente negro de reivindicar sua herança cultural africana. Assim, para tentar integrar a questão da identidade negra com os estudos sobre igrejas evangélicas, cruzaremos os olhares de duas tradições sociológicas. O objetivo é então fazer uma revisão crítica da literatura sobre as religiões evangélicas que estude temas relacionados à questão negra, levando em conta a perspectiva e os conceitos da sociologia das relações étnico-raciais.

Se a literatura chegou a conclusões isoladas sobre a questão negra dentro da igreja evangélica, a revisão bibliográfica que nos propomos a fazer tenta delimitar melhor os desafios dos fiéis negros e o que pode ser a identidade negra dentro da igreja, sem que esta esteja necessariamente em conflito com os princípios cristãos. O presente artigo não tem a pretensão de ser exaustivo em relação à formulação do que pode ou deve ser a identidade negra na igreja; a proposta é levar em conta diferentes pontos de vista para estudar as possibilidades do fiel negro, enquanto

3 Conforme previsto pela lei 10.639/2003, o ensino da história e a cultura afro-brasileira, visa resgatar a importância da herança africana na formação social, econômica e política do Brasil. Essa herança é constituída pela "a história da África e dos Africanos, a luta dos negros no Brasil, [e, por extensão,] a cultura negra brasileira (...)”. (BRASIL, 2003) 
ser negro, de reivindicar a sua etnicidade, sua identidade, sua historicidade ${ }^{4}$. O artigo levanta perguntas como: qual o lugar do negro - como ser não-branqueado - dentro da igreja evangélica? De que forma se manifestam o preconceito, a discriminação e o racismo ${ }^{5}$ dentro da igreja? Qual reconhecimento da identidade negra? Qual identidade negra deve ser reivindicada?

Para a construção deste artigo, nos limitamos a uma revisão de literaturas de vertentes sociológicas diferentes, que aprofundamos usando a pesquisa realizada pela autora entre agosto de 2014 e março de $2015^{6}$ sobre a politização de fiéis evangélicos em São Paulo. Além da observação participante durante cultos, escolas dominicais e momentos de convivência na igreja, as entrevistas sempre incluíam uma parte sobre a identidade racial dos fiéis e suas percepções. Ademais, foram realizadas entrevistas específicas e aprofundadas sobre o tema com uma fiel do Distrito Federal, um pastor de São Paulo e a presidenta da Aliança de Negras e Negros Evangélicos do Brasil (ANNEB), nossa informante pastora no Distrito Federal, para confirmar e reatualizar os dados coletados durante a pesquisa de campo de 2014/2015 ${ }^{7}$. Sem pretender dar conta do contexto protestante no Brasil, o seguinte trabalho se concentra no escopo do protestantismo pentecostal. Contudo, como argumentam Cunha, Lopes e Lui (2017), a “divisão em ondas do pentecostalismo no Brasil (...), ou (...) [a] divisão entre evangélicos históricos ou de missão, de um lado, e pentecostais e neopentecostais do outro" (p. 113) não necessariamente corresponde à realidade evangélica do Brasil. Nesse sentido, os dados de campo foram colhidos a partir das ações de fiéis e pastores de uma denominação pentecostal - em várias Assembleias de Deus -, contudo, com evocações pontuais de uma igreja histórica - a Igreja Presbiteriana do Brasil. Ademais, os autores selecionados para subsidiar as análises estão circunscritos ao universo

4 Este trabalho se inscreve na perspectiva do MNU. O MNU considera como negros os pretos e pardos. Ademais, o termo negro é relacionado ao conceito de raça que, como lembram Fernandes e Souza (2016, p. 105), e remete tanto a características físicas como culturais. A negritude é entendida, segundo a definição de Pinheiro, "como algo não essencial e fechado, sendo uma construção reveladora da consciência da diferença e do pertencimento a um grupo incluso na diáspora africana” (PinHEIRo, 2007, p. 165).

5 Neste nosso trabalho, entenderemos os conceitos de preconceito, discriminação e racismo conforme definidos por Hélio Santos (2001). O preconceito racial é uma opinião pré-formada, sem fundamento, que, a partir dos padrões do próprio grupo racial, constrói uma imagem de inferiorização sobre outro grupo. O racismo constitui um modo de ver que pressupõe a superioridade racial de um grupo sobre outro. Enfim, a discriminação consiste na externalização de uma atitude racista ou preconceituosa, por meio de uma ação que visa a prejudicar.

6 Pesquisa de campo para a dissertação de mestrado. Entrevistas semi-diretivas realizadas com 20 fiéis pentecostais de Igrejas Assembleia de Deus do Estado de São Paulo (3 pastores, 17 fiéis).

7 O nome dos entrevistados (com exceção da pastora Waldicéia) foi mudado para respeitar o seu anonimato. 
pentecostal, mas podem abrir a reflexão sobre os escopos do protestantismo histórico e do neopentecostalismo ${ }^{8}$.

\section{DA SEPARAÇÃO FÍSICA À UNIVERSALIDADE PROTESTANTE: AS RAÍZES HISTÓRICAS DO RACISMO NA IGREJA}

Conforme demonstraremos a seguir, o preconceito, a discriminação e o racismo são expressos, no protestantismo brasileiro - e, hoje, particularmente no pentecostalismo -, dentro de um espectro amplo que vai da separação física dos negros e brancos à universalidade proposta pela liturgia.

Em primeiro lugar, nos interessamos pelas demonstrações explícitas de rejeição dos negros. O protestantismo chega ao Brasil como uma religião branca por duas vias. De um lado, é o mestre da família branca escravocrata que se converte ao protestantismo da Reforma. Como explica Bastide (1960), a conversão do negro ao protestantismo tem dois tipos de explicação: uma histórica e uma religiosa. Em relação à primeira, o negro se converte ao protestantismo por causa da tradição doméstica de incorporação do escravo à vida da família escravocrata. Por ser uma religião resultante da Reforma e que precisa se afirmar e ganhar fiéis, os novos convertidos ao protestantismo se tornam sistematicamente missionários e veem seu senso de responsabilidade acentuado. É assim que os primeiros escravos negros são chamados pelos seus mestres e levados a se converter. Já em 1879, cinco negros ingressam na comunidade presbiteriana de São Paulo. Segundo, o protestantismo histórico se torna mais atrativo para o negro por uma questão religiosa. Enquanto a população negra era rejeitada das igrejas ou das escolas católicas, as instituições evangélicas não rejeitavam os negros: a liturgia protestante aceitava o ser humano independentemente da sua cor (BASTIDE, 1960, p. 494-495), apesar de diferenciação e discriminação operadas dentro da igreja.

Por outro lado, o pentecostalismo - cuja maior igreja, e a segunda mais antiga, permanece a Assembleia de Deus -, é inspirado, como retrata Marina Correa (2013), pelo movimento pentecostal nascido nos Estados Unidos em 1906 e fundamentado nas doutrinas de John Wesley (p. 80). Em 1911, Gunnar Vingren e Daniel Berg dois missionários suecos marginalizados em seu país (principalmente luterano), que emigraram aos Estados Unidos durante a juventude -, chegam em Belém do Pará. A implementação da igreja no Brasil se faz então a partir de um grupo sueco restrito e pobre. A situação econômica limitada dos missionários não permitiu garantir um certo controle do clero sueco sobre os fiéis brasileiros. Além do mais,

8 A título de exemplo Roger Bastide (1960), Aro Pedro Oro (1997) e Ricardo Mariano (1995, 1999). 
o sistema pentecostal no Brasil se fundamenta menos na hierarquia e em um clero diferenciado do resto dos membros do que na importância dada às comunidades socialmente marginalizadas no Brasil católico, como na Suécia luterana. Por conseguinte, os pastores brasileiros gozam desde cedo de grande autonomia. No entanto, e apesar de ser uma religião marginalizada que promove uma liturgia dos socialmente excluídos, o pentecostalismo da Assembleia de Deus - como o das outras igrejas fundadas ao longo do século - continua uma religião branca, em que os negros são acolhidos mas discriminados.

Ao mesmo tempo que a universalidade do protestantismo - tanto histórico quanto pentecostal - leva à aceitação de todos, existe uma separação explícita dentro da igreja. Por muito tempo, durante o culto, os brancos ocupavam a nave enquanto os negros sentavam ou no fundo ou na galeria. Aos poucos, os usos e costumes mudam, e, apesar de um racismo e uma discriminação persistentes, certos negros obtêm cargos dentro da igreja. Porém, o negro não deixa de importunar, como relata a pastora Waldicéia de Moraes Teixeira da Silva de Brasília, ao contar a história dos seus avós Mercedes e Isidoro de Moraes. Ambos eram pioneiros da Assembleia de Deus de São Cristóvão, fundada em 1922, no Rio de Janeiro, por uma família recém chegada de Belém, e sempre causaram um certo desconforto entre a pastoral branca:

Foi quando eles se mudaram para o Jacarezinho, que eles conheceram a Assembleia de Deus de São Cristóvão. Eles foram para lá, se identificaram muito com música, coisa que no Quilombo, é muito forte. Então eles se identificaram muito com a liturgia da Assembleia de Deus. Só que quando eles começaram a incomodar, que o meu avô também era sangue na veia, os dois: a minha avó e o meu avô... Eles começaram a se incomodar com esse lance de negra e negro na galeria, negra e negro sentados lá atrás, com essa forma de como eram discriminados na igreja. Aí minha avó e meu avô começaram a pressionar o pastor presidente, o ministério. Quando eles perceberam que o meu avó estava incomodando muito, o que a presidência de São Cristóvão fez? Enviou meu avô e minha avó abrirem uma igreja na favela do Jacarezinho, onde eles moravam, entendeu? Abrir uma congregação de São Cristóvão no Jacarezinho. Aí meu avô e a minha avó fundaram a primeira Assembleia de Deus do Jacarezinho que está lá até hoje, na rua Darci Vargas, 69. Inclusive, eles fizeram um museu lá e estão lá a minha avó e o meu avô como fundadores da AD do Jacarezinho (Informação verbal)’ .

9 Entrevista concedida por Waldicéia em 30/06/2016. 
Com o passar do tempo, os negros passaram a não entrar "mais pela porta lateral"; como nota Roger Bastide, não houve mais separação física entre os fiéis e os negros começaram a ocupar cargos pastorais. Contudo, à luz da obra de Bastide, é a proposta universalizante do protestantismo que questionamos, para entender que, sob a máscara de uma suposta igualdade, as práticas de preconceito, discriminação e racismo continuam vivas dentro da igreja e assumem outras modalidades.

A liturgia da universalidade do protestantismo - e do pentecostalismo -, fez com que, depois de um tempo, não houvesse separação entre negro e branco dentro da igreja. As entrevistas realizadas confirmam este aspecto, como o faz uma fiel negra de uma Igreja Presbiteriana da Ceilândia - DF:

- Qual foi sua trajetória de mulher negra dentre da igreja?

- Pelo fato de eu ser uma pessoa muito comunicativa, também não enfrentei dificuldades. Fui tomando posição em algumas coisas (...) e fui bem aceita. Nunca tive problema não. Por muitos anos que sou da igreja... (...) acho que já tem uns trinta anos... e sempre tive cargo dentro da igreja (Informação verbal) ${ }^{10}$.

No entanto, apesar de Isaura ter se sentido bem aceita, o seu discurso não evidencia que a questão da igualdade e da universalidade impedem a reivindicação, por parte dos fiéis, de identidades particulares como, por exemplo, a identidade racial - dado avançado pela pesquisa de campo de John Burdick (2002):

existe uma tensão entre o pentecostalismo (...) e o desenvolvimento de identidades sociais fortes como intermediárias entre o universal e o individual [, pois] (...) o pentecostalismo incentiva os crentes a se verem como pertencentes a uma irmandade mundial transcendentes dos que foram salvos (p. 191-192).

10 Entrevista concedida por Isaura em 30/o6/2016. 
Deste modo, reconhecemos a pertinência, até hoje, da teoria da assimilação ${ }^{11}$ de Roger Bastide ${ }^{12}$. Segundo o autor, a assimilação do negro ao protestantismo no Brasil leva à asfixia da sua identidade e herança cultural. Com efeito, no Brasil, o protestantismo negro - facilitado por predicadores negros e igrejas exclusivamente negras que tornaram possível a preservação de traços culturais africanos nos Estados Unidos -, não existe. Não há um protestantismo negro análogo: o protestantismo negro não é diferente do dos brancos (BASTidE, 1960, p. 494). Em outras palavras, segundo o autor, não existe um protestantismo negro e sim, um protestantismo dos negros. Essa distinção semântica feita pelo autor nos ajuda a entender como não são os negros que revisitam o protestantismo, senão os negros que se tornam unicamente protestantes. Com efeito, a problemática que deve nos preocupar aqui tem menos a ver com reinterpretação do protestantismo pelos negros do que a adesão e, portanto, a assimilação dos negros a um projeto religioso que se diz universal. Porém, por ser uma religião trazida por pastores brancos, permaneceu uma religião branca à qual negros foram incorporados no Brasil. Assim,

a igreja não aceitando nenhuma discriminação, a educação religiosa dos Negros [era] absolutamente a mesma que a dos Brancos e (...) a assimilação das crenças ou dos sentimentos [era] completa", suprimindo toda a margem de reinterpretação por parte dos negros (BASTIDE, 1960, p. 496-479).

Voltando à nossa análise, hoje, as condições específicas de aceitação dos negros e o projeto de assimilação dos fiéis negros a um pentecostalismo branco permanecem muito vivos na igreja. Ao comparar as ações da pastoral negra no catolicismo e membros de igrejas evangélicas, autores contemporâneos evidenciam em que medida o discurso pentecostal se opõe à adoção de uma "liturgia negra"

11 Neste trabalho, não adotamos a visão clássica do conceito de assimilação - como fez a escola de Chicago, por exemplo - que vê nela um processo natural, inelutável e inconsciente onde ocorre uma harmonização dos valores e atitudes. Alinhamo-nos ao uso feito por Roger Bastide, como mostraremos no argumento a seguir. Ademais, recorremos à definição de Adbelmalek Sayad (1994) que - ao pensar o papel do sistema republicano francês de integração em contexto de imigração argelina - vê na assimilação a primazia do contrato social e da tradição francesa sobre outras ligações culturais e étnicas. $\mathrm{O}$ autor criticou vivamente seu aspecto universalista e imperialista, anteriormente ressaltado por Abdias do Nascimento (1978) ao citar o herói da libertação de Guiné-Bissau, Amilcar Cabral: “a dominação colonial tem procurado criar teorias, as quais, de fato, são apenas grosseiras formulações de racismo. (...) Este, por exemplo é o caso da chamada teoria da assimilação progressiva das populações nativas, o que acaba sendo unicamente uma mais ou menos violenta tentativa de negar a cultura dos povos em questão" (p. 94-95).

12 Teoria pertinente do autor, apesar de uma reafirmação e difusão de certos preconceitos nos seus escritos, ao usar o termo depreciativo e racista "nègre" em francês, por exemplo. 
e, deste modo, não ressaltam as diferenças raciais (VAlEnte, 1994; SANCHIS, 2002; Oliveira, 2011; Silva, 2014). Portanto, é a partir deste quadro interpretativo que analisaremos a persistência do racismo e, para utilizar um termo da sociologia das relações e das desigualdades raciais, o embranquecimento dos fiéis pentecostais negros (NASCIMENTO, 1978).

\section{A PERCEPÇÃO DA COR E A PERSISTÊNCIA DO RACISMO}

Por um lado, a noção de assimilação e suas implicações se ilustram de diversas maneiras no protestantismo pentecostal contemporâneo, como mostra o exemplo contado pela pastora Waldicéia. Presidenta da Aliança de Negras e Negros Evangélicos do Brasil (ANNEB), a pastora da Assembleia de Deus em Brasília lida diariamente com reclamações e queixas e defende fiéis que sofrem racismo dentro da igreja. Neste caso, a autora da denúncia foi uma jovem fiel de outra denominação que resolveu parar de alisar o cabelo e fazer tranças. Além de uma decisão estética, nos parece que a fiel se pronunciou politicamente, decidindo assumir e reivindicar sua identidade. Durante o culto público do domingo à noite seguinte, a pastora Waldicéia explica como o pastor a expôs e a denunciou na frente da comunidade inteira por ter trançado o seu cabelo e assim ter cedido ao demônio. Frente a "tamanha ofensa" por parte da fiel, o pastor deixou o púlpito e mostrou sua reprovação quando abandonou a plateia e saiu da igreja em pleno culto, deixando a condução do ofício a um segundo pastor. Este exemplo relatado pela pastora é, primeiramente, típico da demonização da herança cultural africana como abordaremos posteriormente com maior profundidade. Ademais, apesar de uma aceitação aparente de todos e da convivência, o episódio relatado pela pastora mostra que a universalidade, em realidade, tem uma cor - ela é branca -, e testemunha um preconceito profundamente arraigado na igreja.

Este exemplo demonstra quão relevante ainda é a ideia por trás da noção de assimilação de Bastide de que o negro é aceito no seio da comunidade evangélica se, e somente se, abandona o que faz dele negro. Nesse sentido, frente à ambiguidade da noção de assimilação, vislumbramos que devemos estudar a liturgia universal do protestante que aceita todo mundo sem discriminação à luz da sociologia das relações e das desigualdades raciais. Primeiro, porque, para o homem negro, existe a necessidade de adjetivação que não há para o branco, como lembra Frantz Fanon ([1952] 2008). Com efeito, o negro não é homem, ele é homem negro. A noção de assimilação revisitada pelo autor nos indica que o negro não é homem a não ser que se torne branco para aceder à condição de ser humano. Ser negro significa uma descida ao inferno, ao não humano. Portanto, o negro pertence a uma zona 
de não-ser, "uma região extraordinariamente estéril e árida, uma rampa essencialmente despojada" (p.26), onde o colocou a colonização. No caso da fiel que escolheu não parecer com uma branca para se afirmar e se elevar à condição de ser humana, ela é imediatamente reenviada a essa zona de não-ser, imediatamente demonizada. Nas palavras de Abdias Nascimento (1978), esse processo consiste no embranquecimento da raça e da cultura negra. A assimilação corresponde então ao que o autor chama de genocídio negro no Brasil como sendo um processo de "racismo mascarado" mas real na sociedade brasileira.

Por outro lado, apesar das dificuldades persistentes, existe uma literatura que defende que hoje em dia há menos racismo dentro da igreja do que na sociedade, como John Burdick (2002). Apesar de também ter observado as diferenças entre a pastoral negra católica e as estratégias históricas de negação das identidades individuais - e, portanto, da negritude - no pentecostalismo, o autor discute os significados de cor e raça na igreja evangélica. Três categorias de argumentos, formulados graças aos dados de uma extensiva pesquisa de campo, fundamentam esta teoria do antropólogo estadunidense. Primeiro, o autor recorre à liturgia do pentecostalismo, cujo maior atrativo:

não só para os negros como para todos os convertidos, é a sua habilidade em criar auto-estima, (...) é insistir em que, mesmo antes da conversão, todo ser humano, por mais indigno que se ache, é objeto da preocupação e do amor constante de Jesus [e que assim, ] (...) a chave para vencer a vergonha foi aceitar-se como preto, escuro ou negro (BURDICK, 2002, p. 193-195).

Segundo, Burdick se apoia na pesquisa realizada em 1996 pelo ISER ${ }^{13}$ para mostrar, objetivamente, que casamentos interraciais ocorrem com mais frequência dentro da igreja do que fora e que, portanto, há menos racismo nas igrejas pentecostais. Enfim, ao dar a palavra a fiéis negros, o autor põe em causa a visão das ciências sociais, de discriminação da identidade negra, ao identificar um número surpreendente alto de esforços iniciativas por parte dos evangélicos para defender sua identidade negra e/ou lutar contra o racismo. Os fiéis declaram efetivamente sentir menos racismo dentro da comunidade evangélica do que na sociedade, e que são livres para expressar sua negritude, no momento dos cantos, por exemplo,

13 Pesquisa realizada em 1996 pelo Instituto de Estudos da Religião, perto de 1332 fiéis evangélicos na cidade do Rio de Janeiro e na região metropolitana, utilizada por Burdick (2002) e Souza (2015). 
pois "uma arena importante para a interseção de valor espiritual e cor é a música" (Burdick, 2002, p. 201).

Entretanto, esta fundamentação conhece limitações devidas a uma certa ingenuidade. Além da crítica ao conceito de continuum de cor, Cleinton Souza (2015), aponta para a ironia de que "é curioso perceber que o mesmo material usado por Burdick para negar a existência do racismo também veio a ser usado para afirmar a presença do mesmo mal social” (p. 282). Primeiro, como o nota Bell Hooks (2009), os casamentos interraciais ou os direitos civis para os negros não constituem uma prova do que o racismo tenha desaparecido. Que pessoas afirmem que:

o racismo tem desaparecido, [o que] normalmente significa que os negros / as pessoas de cor ganharam direitos civis suficientes através de leis e práticas de anti-discriminação, que já não [estão] sujeitos ao terrorismo racial constante ou punições brutais evidentes com base na raça, não quer dizer que não existe mais racismo, discriminação e preconceito institucionais ou nas relações interpessoais (p. 10).

No contexto da igreja, embora haja uma certa aceitação da cor e da identidade negra pela comunidade evangélica, a visão sobre o negro não deixa de ser a de um negro exótico, e é carregada de preconceitos - sejam eles positivos ou negativos. Ademais, ao declarar que negros são mais abertos do que brancos aos dons do Espírito Santo, John Burdick opõe dois tipos de fiéis para mostrar a abertura que existe na igreja. Reconhece que o racismo não desapareceu, por um lado, pois certos fiéis acham que os negros só se exibem durante o canto. No entanto, o autor mostra, por outro lado, que a maioria da comunidade é tolerante e aberta à identidade negra na medida em que reconhecem as qualidades do negro no comprometimento à religião, para escapar das forças diabólicas dos cultos afro-brasileiros; ou no canto, ao naturalizar uma suposta emotividade negra. Voltando à nossa análise, percebemos que, apesar da comunidade evangélica querer elogiar os fiéis negros, essas falas levantam dois tipos de problemas. Primeiro, como mostra Márcia Leitão Pinheiro (2007), elas "não incorporam uma reflexão sobre etnicidade" (p. 173). Segundo, ao nosso ver, elas evidenciam a demonização da herança religiosa africana assim como a essencialização da raça negra, as quais mostram que o racismo e o preconceito não desapareceram.

Outra hipótese, baseada na literatura e na pesquisa de campo, nos leva a questionar a afirmação de que há menos racismo, discriminação e preconceito dentro da igreja. Sabemos que, por serem religiões de convertidos, ao invés do catolicismo, 
os crentes pentecostais sempre buscam reafirmar sua identidade religiosa. A identidade evangélica se revela como uma parte muito importante dos fiéis, sempre prontos a defender a sua igreja. Como mostra Ariane Zambiras para questões de gênero, os fiéis tentam desconstruir a acusação de intolerância que recebem as igrejas evangélicas (2014, p. 243). Portanto, no caso do nosso estudo, é razoável argumentar que, ao receber perguntas diretas sobre o racismo, os crentes podem sentir um ataque à sua igreja e tender a valorizá-la, na sua preocupação de se abrir ao mundo. Deste modo, existe a possibilidade que os fiéis ignorem ou amenizem experiências de racismo ou de discriminação dentro da igreja.

Portanto, como analisa Souza (2015), também vislumbramos uma dissimulação do preconceito racial, da discriminação e do racismo dentro da igreja. Graças ao aporte teórico de Florestan Fernandes (1972), o autor conclui que esses valores e comportamentos passaram a ser "condenados no plano ideal, mas não repelidos no plano da ação concreta e direta" (SouzA, 2015, p. 289). Ademais, se houve uma evolução e uma aceitação relativa da cor, a questão da herança cultural africana e de sua religiosidade continua sendo problemática, tanto no plano das ideias quanto da prática cotidiana, como já identificamos em duas situações em que sobressai a relação conflitiva das religiões evangélicas com as religiões de matriz africana. Por isso, dedicamos uma parte da nossa discussão ao tratamento da herança cultural e religiosa africana pelas igrejas protestantes históricas, mas sobretudo, pentecostais e neopentecostais.

\section{NOVAS QUESTÕES LIGADAS À REJEIÇÃO E ÀS RESSIGNIFICAÇÕES DA HERANÇA CULTURAL AFRICANA}

Fizemos a escolha de dedicar-nos ao estudo da posição da herança cultural e religiosa africana na igreja por ser um aspecto fundamental da identidade negra por vários motivos. Primeiro porque, como vimos na introdução, as culturas afro-brasileiras conseguiram um lugar específico na história do Brasil e das populações negras do país, por meio da lei 10.639/o3. Por conseguinte, elas são oficialmente reconhecidas como parte integrante da identidade negra. Segundo, o legado africano é muito relevante pela atenção que lhe dão as igrejas evangélicas, sobretudo pentecostais e neopentecostais. As relações destas últimas com a herança das religiões de matriz africana são um aspecto problemático da questão estudada.

Para entendermos melhor a profunda e complexa conexão entre as igrejas evangélicas e a herança da cultura africana, trataremos primeiro da rejeição histórica e seus motivos. De maneira geral, como vimos através dos estudos de Roger Bastide, a África como um todo sempre viu o seu acesso às igrejas históricas. Esta 
afirmação também se verifica na fala de Isaura, que, a priori, não via problema em afirmar sua negritude na igreja:

Estou lembrando aqui de um assunto... Há uns cinco anos atrás, fundei aqui com as meninas uma banda de música de percussão. E eu queria muito levar para a igreja. E pouca igreja aceitou. Porque eles achavam que tinha a ver com raízes africanas. Essas coisas, para eles, são demoníacas (Informação verbal) ${ }^{14}$.

Esta demonização das raízes africanas também tem lugar nas igrejas pentecostais. Vários fiéis ou pastores apelam à Bíblia para justificar a necessidade de deixar do lado de fora da igreja aspectos remetentes à cultura africana. É assim que o pastor Paulo, de uma Igreja Assembleia de Deus em São Paulo, faz uso do Levítico 19:31: "não vos virarei para os adivinhadores e encantadores; não os busqueis, contaminando-vos com eles. Eu sou o Senhor vosso Deus", para afirmar que os cultos afro-brasileiros são "um rumo da feitiçaria" e assim demonizá-los porque consultam mortos ou adoram outros deuses que não são Deus ${ }^{15}$.

Portanto, há uma verdadeira demonização da cultura africana e das religiões de matriz africana por parte das grandes vertentes evangélicas do Brasil. Edir Macedo, fundador da Igreja Universal do Reino de Deus até considera que "a Umbanda, Quimbanda, Candomblé e o espiritismo de um modo geral, são os principais canais de atuação dos demônios” (MACEDO, 1987, p. 113).

A demonização das religiões de matriz africana se concretiza de várias maneiras. Em primeiro lugar, e na maioria dos casos, os ataques assumem a forma de agressões verbais durante o culto ou durante o discurso proselitista dos pastores, missionários ou fiéis das igrejas evangélicas. Gonçalves da Silva (2007) estabelece uma tipologia para identificar as diferentes práticas de demonização que vai dos ataques discursivos que mencionamos aqui, agressões físicas contra terreiros ou "cerimônias religiosas afro-brasileiras", a ataques "decorrentes das alianças entre igrejas e políticos evangélicos" (p. 216). Com a eleição de cada vez mais representantes evangélicos, o autor observa uma representação política destes interesses e que os políticos evangélicos articulam ações para impedir a realização dos cultos, tentando proibir, por exemplo, o sacrifício animal no Código Estadual de Proteção das Animais do Rio Grande do Sul (Silva, 2007, p. 220). Trata-se de uma verdadeira institucionalização dos princípios cristãos, que tenta, através do

14 Entrevista concedida por Isaura, em 30/06/2016.

15 Entrevista concedida pelo Pastor Paulo, em 04/o6/2016. 
direito e de instrumentos legais, legitimar a demonização de religiões de matriz africana.

Parte da literatura existente que explora a questão da demonização dos cultos afro-brasileiros pelas igrejas evangélicas a analisa como uma disputa em um mesmo mercado religioso. Por um lado, surge uma análise socioestrutural dos ataques às religiões de matriz africana em razão de uma luta simbólica. Nesse sentido, Ari Pedro Oro (1997) a qualifica de "concorrência religiosa entre iguais" pois são "expressões religiosas que disputam fiéis que compartilham além do mesmo nível social, dos mesmos códigos e cognitivos" (p. 16-17) ${ }^{16}$. Em uma perspectiva semelhante, Silva (2007) observa que um dos primeiros motivos de combate a essas religiões afros seria "uma forma de atrair fiéis ávidos pela experiência de religiões com forte apelo mágico; extáticas, com a vantagem da legitimidade social conquistada pelo campo religioso cristão" (p. 12). Por outro lado, Ricardo Mariano (1999) também vê a disputa como uma concorrência mercadológica, porém, aproxima-se de uma leitura weberiana da noção de mercado religioso - de bens de salvação -, como espaço de conquista de legitimidade e novos devotos em um jogo de soma zero. Nesse sentido, a necessidade dos evangélicos entrarem em competição com os cultos afro-brasileiros se explicaria pois estes últimos seriam "os maiores concorrentes no mercado de soluções simbólicas e prestação de serviços religiosos para os problemas materiais e espirituais dos estratos pobres da população" (p. 108-109). Entretanto, de modo geral, os diferentes autores percebem essa rejeição como uma forma das igrejas evangélicas conquistarem um público mais amplo.

A lógica da concorrência se torna muito mais relevante ao perceber que as religiões evangélicas dialogam com as religiões de matriz africana. A fim de captar novos fiéis, as igrejas evangélicas - mas sobretudo neopentecostais - devem reconhecer os cultos afro-brasileiros para poder atacá-los mais eficientemente:

os pastores "acatam" todo o panteão afro-brasileiro: falam com eles, dão credibilidade a sua existência. Seria bastante ineficaz chegar para uma pessoa que durante anos recebeu um determinado guia dizendo que tais coisas não existem. O que o pastor faz é mostrar que elas existem, mas que ele tem poder sobre elas (...). Esse poder é reforçado quando o pastor se mostra capaz não só de invocá-las mas também de fazê-las falar, confessar sua origem demoníaca e, por fim, numa prova inconteste de sua força, expulsá-las. (SOAREs, 1990, p. 87).

16 Aqui entrarão em consideração só as igrejas pentecostais (e neopentecostais) que historicamente miraram um público mais pobre e humilde, ao contrário do protestantismo histórico. 
Contudo, o diálogo entre as duas entidades vai além da busca de uma concorrência eficiente no mercado religioso no que diz respeito às igrejas pentecostais e ainda mais neopentecostais ${ }^{17}$. As práticas tais como o transe, o exorcismo, o falar em línguas, entre outras, são interiorizadas por fiéis neopentecostais e se aproximam muito de ritos afro-brasileiros. O exemplo da Igreja Universal do Reino de Deus é mais flagrante ainda:

A IURD também se apropria, (...) em relação aos cultos afro-brasileiros, entre muitos, o uso de sal grosso, do galho de arruda, fechamento de corpo, distribuição da bala ungida para as crianças no dia de Cosme e Damião e a invocação das entidades para que se manifestem. (Bonfatti, 2000, p. 89).

Para explicar tal aproximação, Ari Pedro Oro (1997) usa o conceito de alinhamento de marcos interpretativos ou frame alignment da realidade, de Snow et al. $(1986)^{18}$. Ao usar as categorias de frame amplification e frame transformation, o autor analisa como as igrejas neopentecostais às vezes se apropriam de ritos e práticas afrobrasileiros, ampliando-os e reforçando-os; além disso, reutilizam marcos interpretativos de religiões de matriz africana buscando sua transformação, sua ressignificação. Igrejas neopentecostais, sobretudo a Igreja Universal do Reino de Deus, retomam certas práticas dos terreiros, como "a insistência de manifestações nos templos (...), dos espíritos da "macumba"; a ruptura de um tradicional modelo comunitário evangélico (...), e da introdução de uma relação quase "clientelista" com os fiéis" (Oro, 1997, p. 26), e transformam outras. Por exemplo, mira-se a ressignificação da prática do exorcismo, que não é mais visto como o "ponto culminante de extrema sacralização do ritual” (ORO, 1997, p. 28), senão como um "polo negativo extremo de manifestação do sagrado por tratar-se da irrupção do mal” (Almeida, 1996, p. 77). Assim, a estratégia do neopentecostalismo é de tornar-se parecido com o inimigo demonizado a fim de distanciar os indivíduos que frequentam terreiros e convertê-los ao Evangelho.

Portanto, grande fração da literatura trata da questão da hostilidade evangélica para com os cultos afro-brasileiros à luz de uma lógica de concorrência de mercado.

17 O culto das igrejas protestantes históricas não envolve estas práticas que encontramos nas religiões de matriz africana.

18 Ari Pedro Oro usa a definição do frame alignment de Snow que "é utilizado (...) para explicar o recrutamento de indivíduos em movimentos sociais ou a conversão à novos movimentos religiosos (...) consiste em "estabelecer uma conexão entre as orientações interpretativas dos indivíduos e a dos grupos que pretendem recrutá-los, de tal forma que algum tipo de interesse, valores e crenças dos indivíduos vejam-se como congruentes e complementários com as atividades, objetivos e ideologia do grupo" (SNOw ET AL., 1986, p. 464 apud Oro, 1997, p. 26) 
Sem dúvidas, o protestantismo histórico, o pentecostalismo e o neopentecostalismo são religiões historicamente sectárias que precisam se afirmar negando outras religiões. No entanto, apesar de Cecília Mariz declarar que "os pentecostais não demonizam apenas o oprimido socialmente (como seria o caso das religiões afros), mas também o socialmente mais bem sucedido (como o caso dos adeptos da Nova Era)" (1996, p. 237), consideramos pertinente introduzir uma nuance. É mais difícil se atacar com tanta veemência ao catolicismo por ser a primeira religião do país, mesmo que em declínio (IBGE, 2010). Além do mais, a competição não pode ser considerada como o único fator responsável por essa perseguição. No final dos anos 1990, Ricardo Mariano parece ser um dos poucos autores a salientar a

perseguição que também decorria da existência, nos séculos passados e no início deste, da extensa série de práticas, discursos e saberes elitistas fundamentados no racismo, no positivismo, no etnocentrismo, no evolucionismo e em preconceitos culturais variados que pressupunham e afirmavam a inferioridade racial e intelectual do negro e, por conseguinte, de sua cultura religiosa (MARIANO, 1999, p. 117).

Assim, o negro, no nível mais baixo da hierarquia social e cuja identidade é constantemente desprezada e oprimida, pode ver na conversão a uma religião evangélica - próxima dos cultos afro-brasileiros - uma possibilidade de ascender socialmente e sair dessa zona de não-ser. Nesse sentido, Roger Bastide afirma que

assim, nesta religião de transe mística, o que nos parece mais dominante para o homem de cor, é esta vontade puritana, este esforço para sair da classe baixa, emburguesar-se para assim dizê-lo. É no momento no qual parece, agitado de tremores, falando línguas estrangeiras, dominado pelo Espírito Santo, de estar mais perto da África, que ele é, na verdade, o mais longe, que ele mais se ocidentaliza (BASTIDE, 1960, p. 499).

Após os trabalhos de Roger Bastide, a literatura que estudou a opressão dos cultos afro-brasileiros pareceu não reconhecer mais que a discriminação se fundamentava no racismo, até Mariano (1999). Por sua vez, Silva (2007, 2011, 2014), reintroduz mais explicitamente esta variável - muitas vezes tida como óbvia ou esquecida -, e faz desta o pressuposto da sua análise. Ademais, a literatura sociológica que estuda as relações e as desigualdades raciais nos permite aprofundar esta visão segundo a qual as culturas africanas não são só perseguidas por 
motivos estratégicos, já que, como afirma Nascimento (1978), “desde os inícios da colonização, as culturas africanas, chegadas nos navios negreiros, foram mantidas num verdadeiro estado de sítio" (p.101). Ademais, "há um indiscutível caráter mais ou menos violento nas formas, às vezes sutis, da agressão espiritual a que era submetida a população africana” (p. 101). Portanto, a perseguição persistente dos cultos afro-brasileiros tem seu fundamento nessa perspectiva de superioridade do branco e reforça o que o autor chama de genocídio negro no Brasil.

\section{AS POSSIBILIDADES DO SER NEGRO DENTRO DA IGREJA}

À guisa de conclusão, voltamos à noção de identidade negra e ao que ela nos oferece para o ambiente da igreja evangélica. A discriminação persistente e a ligação contígua e complexa entre as religiões evangélicas e de matriz africana nos levam a interrogar de novo a noção de identidade negra e a necessidade da afirmação de uma ancestralidade africana para se considerar e se reconhecer como negro. É preciso reivindicar a herança cultural e religiosa africana para consolidar sua identidade negra? Como se pode combater o preconceito contra os negros na igreja? São as identidades negra e pentecostal irreconciliáveis ou é "possível falarmos de uma cultura negra evangélica” (SANTOS, 2013, p. 12)?

Como aponta Silva (2011), uma força negra do protestantismo evangélico se constituiu no Movimento Negro Evangélico (MNE) que no começo dos anos 1980, no final da ditadura militar, iniciou um trabalho de reflexão sobre a questão racial e de elaboração de uma identidade negra dentro de uma perspectiva cristã. Esse movimento se inspirou no modelo estadunidense de ação política e deveu-se à iniciativa de pastores negros. Ele responde ao antagonismo que evocamos afirmando que não havia "necessidade de relacionar identidade negra com as religiões afro-brasileiras" (p. 298). Existe então uma tendência dentro do protestantismo evangélico negro de não reconhecer e se contrapor à necessidade histórica para o Brasil e particularmente para as populações negras de valorizar a herança cultural e religiosa africana. A criação do MONEBA, Associação Nacional do Movimento Negro Evangélico se inscreve nesta mesma perspectiva e permitiu a Reginaldo Germano, deputado federal no estado da Bahia de 1999 a 2007, entrar "na militância da causa negra sem abandonar algumas de suas convicções (ou preconceitos)", sem ter que cultivar algum tipo de reconhecimento às religiões de matriz africana (SANTos, 2013, p. 6).

Frente a essa visão conflitante de uma identidade negra cristã que continua rejeitando as religiões de matriz africana, o antropólogo Livio Sansone (2004) vai mostrar que a noção de comunidade negra é problemática pois a negritude, 
como vimos na introdução, não representa uma entidade dada, mas uma construção social contingente (p. 24). Existe então uma impossibilidade de chegar ao consenso para definir o que é a identidade negra, apesar das mobilizações de um movimento negro tampouco muito unificado e dos avanços legais, como mencionamos. Segundo ele,

o termo comunidade negra, usado com bastante frequência nos círculos políticos baianos e nos meios de comunicação de massa, não se refere à totalidade da população negra nem define uma "comunidade negra" (...) A comunidade negra representa, portanto, apenas uma pequena parcela da vida social e cultural negra de Salvador (p.114).

Por isso, o autor vai repensar as relações raciais, não em termos de identidade senão de negritude sem etnicidade. Essa ideia de negritude sem etnicidade encontra-se reverberada no Estatuto da Igualdade Racial que chegou a um consenso identificando "o negro não a partir de sua aparência ou de determinadas características étnicas, mas pelo fato de que historicamente o negro vem sendo discriminado na sociedade" (SAnTos, 2013, p. 13). Deste modo, o reconhecimento do negro passaria pelo fim do preconceito racial, da discriminação e do racismo, e não necessariamente pela afirmação de uma identidade própria.

Porém, em contraponto a essas visões, podemos apontar para iniciativas que não entendem identidade negra e identidade evangélica em termos de contradição. Por um lado, existem novos passos de uma unificação das identidades negra e evangélica, os quais se dão fora do próprio contexto eclesial. Na literatura, esta possibilidade é ilustrada pelos estudos de Márcia Leitão Pinheiro, sobre religião, raça e música $(2007,2009)$. A autora mostra "black music gospel / "música negra" como um âmbito de possibilidades para a emergência de formas de se pensar e ser negro, isto é, de construir e veicular uma noção de negritude" (PINHEIro, 2007, p. 164). São postas em evidência ações independentes de produtores e cantores negros e membros de igrejas históricas ou neopentecostais, capazes de mudar as perspectivas sobre o negro evangélico, capazes de "alterar o modo como (...) [a cultura negra] e os fiéis "negros" são definidos no meio evangélico" (p. 166). Outras formas individuais, em que os negros evangélicos se constituem e afirmam fora das quatro paredes da igreja, também se verificaram na pesquisa de campo realizada para este trabalho, como mostra o exemplo de Lea, de uma Igreja Assembleia de Deus em São Paulo. Durante a entrevista, ela várias vezes defendeu sua negritude, a de sua filha que deixou de alisar o cabelo, e atacou com veemência uma mídia 
que ignorou os atentados provocados por Boko Haram na Nigéria e só reportava os ataques ao jornal semanal Charlie Hebdo em Paris em janeiro de 2015, ilustra então que uma via de reconciliação é possível:

- Você postou um dia no Facebook: “Je suis nigériane”. Por quê?

- É! Até procurei para escrever direito. Lembro porque nem o grupo de intelectualidade afrodescendentes que eu curto comentou sobre isso. Estava todo mundo falando "Je suis Charlie", mas e a Nigéria, onde fica em tudo isso? Ninguém falou nada. Lá o pessoal sofre, e sofre muito. E muito mais pessoas. Tudo bem que lá [em Paris], também foi dolorido, foi triste. Mas lá na África? (Informação verbal) ${ }^{19}$.

Entretanto, a literatura e a pesquisa de campo revelam que esses atos de reconciliação individuais geralmente existem fora da igreja e carecem de apoio institucional. Neste sentido, Pinheiro (2007) afirma que "ainda assim, os produtores apontam para o não reconhecimento de suas iniciativas, terminando por atuar nas margens de seu meio religioso" (p.168).

Por outro lado, existe um trabalho incipiente de defesa institucional de uma identidade negra dentro da igreja, como vimos com a ANNEB, anteriormente evocada. A pastora Waldicéia retrata seu papel com vigor e convicção:

Fui para São Paulo fazer uma palestra num fórum, que a gente da ANNEB sempre faz quando alguém é vítima de discriminação, preconceito e racismo na igreja... A gente aparece lá, primeiro para conversar com a vítima e dar a opção de irmos no próximo culto em que aconteceu: um monte de preto, tudo caracterizado, turbante, mante de preto, etc. se sentar nos primeiros bancos da igreja de frente para o pastor e colocar no meio da gente a vítima. Sem falar nada, assiste o culto normalmente. Aí quando o culto termina, eu como presidenta da ANNEB procuro o pastor (...): "Pastor, chegou até nós a denúncia tal da nossa irmã fulana de tal, nós já ouvimos ela, queremos ouvir o senhor”. Quando ele termina, falamos: “(...) Nós somos do movimento social negro, e segundo a lei tal tal tal, o que o senhor fez é crime. Nós já colocamos ela [a vítima] para escolher: ou juntamos todos nós e vamos com ela e um advogado em uma delegacia denunciar o senhor pela prática de discriminação, preconceito e racismo, ou o

19 Entrevista concedida por Lea em 31/01/2015. 
senhor abre a igreja a semana que vem para que nós façamos um fórum temático sobre discriminação, preconceito e racismo na igreja protestante, onde nós vamos chamar representante do movimento social negro na primeira mesa. $\mathrm{Na}$ segunda mesa, eu como presidenta da ANNEB, vou falar sobre a legislação que existe hoje sobre discriminação, preconceito e racismo. O presidente da ANNEB nessa unidade da federação vai falar sobre discriminação, preconceito e racismo na Bíblia. E depois a gente abre para o debate. E no final, o senhor se retrata na frente de todas e todos que estão ali. O senhor escolhe, são duas alternativas que o senhor tem”. Não precisa nem dizer que todos eles escolhem o fórum, né... (Informação verbal) ${ }^{20}$.

Vários pontos na fala da pastora aparecem como surpreendentes e interessantes para o nosso estudo. A ANNEB se posiciona como uma organização que articula membros e líderes evangélicos e que, oficialmente, promove e reforça a ação do Movimento Negro Evangélico para "comungar experiências, reflexões e propostas concretas visando à mobilização da igreja na contribuição de uma sociedade mais justa e igualitária” ${ }^{21}$. Mas na sua busca de reparação das injustiças sociais, econômicas e históricas impostas à população negra e ao vestir indumentárias africanas, a ANNEB ressalta a necessidade de ligação profunda da população negra brasileira com a sua herança cultural africana. $\mathrm{O}$ uso provocativo de vestes africanas visa a mostrar que não existe antagonismo entre as identidades negra e evangélica e busca a superação de qualquer forma de intolerância, também religiosa. A ANNEB se coloca como alternativa ao preconceito, à discriminação e ao racismo formalizados na igreja, e constitui um esboço de valorização institucional de uma identidade negra que compreende a cultura e religiosidade africana como um legado a ser preservado e respeitado. Em um cenário institucional evangélico que alimenta um discurso que demoniza a África como um conjunto homogêneo, a organização aparece como uma exceção e porta a voz de fiéis que querem afirmar sua negritude ou de outros que não estão necessariamente de acordo com o discurso institucional que despreza e oprime as culturas africanas.

Os caminhos - tanto individuais quanto institucionais - de possível reconciliação que mencionamos constituem, portanto, uma primeira conclusão para o nosso trabalho incipiente. A partir da ancoragem histórica do nosso estudo e das questões contemporâneas de dissimulação do preconceito e de rejeição da herança

20 Entrevista concedida por Waldicéia em 02/07/2016.

21 Disponível em http://annebbahia.blogspot.com.br/p/quem-somos.html, acessado em 02/05/2017. 
cultural e religiosa africana, podemos deduzir que a socialização - tanto primária quanto a realizada na igreja - de evangélicos negros é marcada por imposições contraditórias: há de negar sua identidade racial para ser um bom cristão. No entanto, há uma tendência que parte de iniciativas privadas ou de movimentos que precisam ser consolidados - mas que as instituições eclesiais têm dificuldade em acompanhar -, que mostra que se abrem caminhos de recomposição do pano de fundo onde os fiéis conseguem sobrepor de maneira mais serena a identidade cristã e a identidade negra, a qual pode ser reivindicada de maneira liberada.

\section{REFERÊNCIAS BIBLIOGRÁFICAS}

Almeida, Ronaldo de. A Universalização do Reino de Deus. Dissertação de mestrado. Faculdade de Antropologia Social da Unicamp, Campinas, 1996.

ANNEB BAHIA. QUEM SOMOS. DISPONÍVEL EM: HTTP://ANNEBBAHIA.BLOGSPOT. COM.BR/P/QUEM-SOMOS.HTML, Acesso em: 02 mai. 2017.

BASTIDE, Roger. Les religions africaines au Brésil. Paris: Presses Universitaires de France, [1960] 1995.

Bonfatti, Paulo. A expressão popular do sagrado - Uma análise psico-antropológica da Igreja Universal do Reina de Deus. São Paulo: Paulinas, 2000.

BRASIL. Inclui no currículo oficial da Rede de Ensino a obrigatoriedade da temática "História e Cultura Afro-Brasileira”. Lei No 10.639, o9 de janeiro de 2003.

Burdick, John. "Pentecostalismo e identidade negra no Brasil: mistura impossível?”. In: MAGGIE, Yvonne; Rezende, Claudia Barcellos (orgs). Raça como retórica: a construção da diferença. Rio de Janeiro: Civilização Brasileira, 2002, p.185-212.

Correa, Marina. Assembleia de Deus. Ministérios, Carisma e Exercício de Poder. São Paulo: Fonte Editorial, 2013.

Cunha, Christina Vital da; Lopes, Paulo Victor Leite; Lui, Janayna. Religião e política: medos sociais, extremismo religioso e as eleições 2014. Rio de Janeiro: Fundação Heinrich Böll, Instituto de Estudos da Religião, 2017.

FAnON, Frantz. Pele Negra, Máscaras Brancas. Salvador: Ed. UFBA, [1952] 2008.

Fernandes, Florestan. O negro no mundo dos brancos. São Paulo: Global, [1972] 2007.

Fernandes, Viviane Barboza e SouzA, Maria Cecilia Cortez Christiano de. Identidade Negra entre exclusão e liberdade. Revista do Instituto de Estudos Brasileiros, n. 63, abr. 2016. Guimarães, Antônio Sergio Alfredo. Como trabalhar com "raça” em Sociologia. Educação e Pesquisa, v. 29, n. 1, 2003.

Hooks, Bell. Writing beyond race. Living Theory and Practice. New York/London: Routledge Taylor \& Francis Group, 2009. 
IвGE. CENSO DE 2010. DISPONÍVEL EM: HTTP://CENSO2010.IBGE.GOV.BR/, acesso em 02/05/2017.

MACEDo, Edir. Orixás, Caboclos e Guias: deuses ou demônios? Rio de Janeiro: Universal Produções, 1987.

Mariano, Ricardo. Neopentecostalismo: os pentecostais estão mudando. Dissertação (Mestrado em Sociologia). São Paulo, Faculdade de Filosofia Letras e Ciências Humanas, Universidade de São Paulo. São Paulo, 1995.

. Neopentecostais: Sociologia do novo pentecostalismo no Brasil. São Paulo: Edições Loyola, 1999.

Mariz, Cecília. "Il demonio e i pentecostali in Brasile". In: Cipriani, Roberto; Eleta, Paula e NeSTI, Arnaldo (orgs). Identità e mutamento nel religioso latinoamericano. Milano: Franco Angeli, 1996, p.229-244.

Nascimento, Abdias do. O genocídio do negro brasileiro. Processo de um racismo mascarado. Rio de Janeiro: Editora Paz e Terra, 1978.

Quilombismo: documentos de uma militância pan-africanista. Petrópolis: Vozes, 1980.

OliveIrA, Rosenilton Silva de. Orixás: a manifestação cultural de Deus: uma análise das liturgias católicas inculturadas. Dissertação (Mestrado em Antropologia Social). São Paulo, Faculdade de Filosofia, Letras e Ciências Humanas, Universidade de São Paulo, 2011.

Oro, Ari Pedro. Neopentecostais e Afro-brasileiros: quem vencerá esta guerra? Debates do NER, Porto Alegre, ano 1, n. 1, nov. 1997.

Pinheiro, Márcia Leitão. Música, Religião e Cor. Uma leitura da produção de black music gospel. Religião e Sociedade, v. 27, n. 2, 2007.

. Dinâmicas da religiosidade: experiências musicais, cor e noção de sagrado. Stockholm Review of Latin American Studies, n. 4, mar. 2009.

SANChis, Pierre. "Inculturação? Da cultura à identidade, um itinerário político no campo religioso: o caso dos agentes de pastoral negros". In. CAROSO, Carlos; BACELAR Jeferson (org.). Faces da tradição afro-brasileira: religiosidade, sincretismo, anti-sincretismo, reafricanização, práticas terapêuticas, etnobotânica e comida. Rio de Janeiro/ Salvador: Pallas /CNPq, 2002, p.171-210.

SAnsone, Lívio. Negritude sem etnicidade. O local e o global nas relações raciais e na produção cultural negra do Brasil. Salvador/Rio de Janeiro: EdUFBA/Pallas, 2004. SAntos, Adriana Martins dos. Identidade negra e neopentecostalismo: o caso Reginaldo Germano. XXVII Simpósio Nacional de História, Natal - RN, 22 a 26 de Julho 2013. SAntos, Hélio. "Discriminação racial no Brasil". In SABóiA, Gilberto. Anais de seminários regionais preparatórios para a Conferência Mundial contra o Racismo, 
Discriminação Racial, Xenofobia e Intolerância Correlata. Brasília: Ministério da Justiça, 2001.

SAYAD, Abdelmalek. Qu'est-ce que l'intégration. Hommes et Migrations, n. 1182, dezembro 1994.

SiLva, Vagner Gonçalves da. Neopentecostalismo e religiões afro-brasileiras: significados do ataque aos símbolos da herança religiosa africana no Brasil contemporâneo. Mana, v. 13, n. $1,2007$.

"Religião e identidade cultural negra: católicos, afrobrasileiros e neopentecostais”. Cadernos de Campo, São Paulo, v.20, n. 20, jan./dez. 2011. . Religion and black cultural identity. Roman Catholics, Afro-Brazilian and Neopentecostalim. Vibrant, v. 11, n. 2, jul./dez. 2014.

Snow, David et al. Frame alignment processes, micromobilization, and movement participation. American Sociological Review, v. 51, n. 4, 1986.

SoAres, Mariza de Carvalho. "Guerra santa no país do sincretismo". In: Landim, Leilah (org.). Sinais dos tempos - Diversidade religiosa no Brasil. Rio de Janeiro: ISER, 1990. Souza, Cleinton. Racismo estrutural, dissimulação do preconceito e pentecostalismo brasileiro. Reflexus, ano IX, n. 14, 2015/2.

Zambiras, Ariane. La Politique inspirée: Controverses publiques et religion aux ÉtatsUnis. Paris: Karthala, 2014. 